\title{
A SUSTENTABILIDADE NO ENSINO TÉCNICO EM ADMINISTRAÇÃO: CURRÍCULO OFICIAL OU OCULTO
}

\author{
J. F. ZAMBERLAN, R. P. BORTOLOTTO", J. P. RAMOS, H. CABRAL, G. M. JESUS, D. O. LEÃO e K. FRIZZO \\ Universidade Federal do Santa Maria \\ rafaelpbortolotto@gmail.com**
}

Artigo submetido em outubro/2013 e aceito em fevereiro/2015

DOI: $10.15628 /$ holos.2015.1703

\section{RESUMO}

A preocupação em aliar desenvolvimento econômico e social com a preservação dos recursos naturais é objeto de pesquisas nas mais diversas áreas do conhecimento, dentro do que rege o tema sustentabilidade. Torna-se imperativo que as instituições insiram estes temas em seus currículos. Sobre esta perspectiva, o objetivo do nosso trabalho foi verificar qual a importância dada e se está presente a temática da sustentabilidade no currículo do curso Técnico em Administração. Para a pesquisa, foram entrevistados o coordenador do curso e os docentes que ministram as disciplinas técnicas do
Colégio Politécnico da Universidade Federal de Santa Maria. A escolha dos docentes de acordo com as competências técnicas que ministram no curso Técnico em Administração. Os resultados mostraram que a sustentabilidade é importante para o curso e possui aplicabilidade na área sendo tratada por muitos docentes de forma transversal. Concluiu-se que a sustentabilidade encontra-se no currículo oculto por ser abordada no curso de forma implícita em outros conteúdos devido à iniciativa própria dos docentes, não constando no currículo oficial da escola.

PALAVRAS-CHAVE: Educação profissional, sustentabilidade, currículo, desenvolvimento.

\section{SUSTAINABILITY IN TECHNICAL EDUCATION IN ADMINISTRATION: OFFICIAL OR HIDDEN CURRICULUM}

\begin{abstract}
The concern in combining economic and social development with the preservation of natural resources is the subject of research in various fields of knowledge within the governing sustainability. It is imperative that institutions enter these themes in their curricula. On this view, the objective of our study was to assess how important this is and if given the theme of sustainability in the curriculum of the course in Technical Management. For the research, we interviewed the course coordinator and the teachers who teach the technical disciplines of the Polytechnic College of the
\end{abstract}

Federal University of Santa Maria. The choice of teachers in accordance with the technical expertise who teach the course in Technical Management. The results showed that sustainability is important for the course and has applicability in the area being treated for many teachers transversely. It was concluded that sustainability is the hidden curriculum to be covered in the course by implication other content on their own initiative due to the teachers, not included in official school curriculum.

KEYWORDS: Professional education, sustainability, curriculum, development. 


\section{INTRODUÇÃO}

A preocupação em aliar desenvolvimento econômico e social com a preservação dos recursos naturais é objeto de pesquisas nas mais diversas áreas do conhecimento, pois todas estão inseridas em um mesmo contexto. Portanto, torna-se imperativo que as instituições de ensino sejam elas de qualquer nível, inseridos em seus currículos, tenham a temática e os conceitos de sustentabilidade.

Atualmente os temas ambientais são emergentes em todas as esferas sociais, empresariais e acadêmicas, sendo alvo de discussões e estudos. O processo educacional pósrevolução industrial objetivou formar mão de obra qualificada para o mercado e este tem sido o modelo educacional atual. Dentro de uma política de expansão do ensino técnico e superior, onde se formam profissionais para o mercado de trabalho, e que os mesmos, em muitas oportunidades serão aqueles que formarão opinião no futuro, a noção de sustentabilidade é imperativa. Cidadãos que receberão um mundo, ninguém sabe, em que condições, terão o desafio de vencer barreiras e quebrar paradigmas, construindo um futuro para as gerações subsequentes.

O respeito às diversidades culturais das minorias e de credos, a não espoliação desmedida dos recursos naturais, um desenvolvimento econômico mais justo e de longo prazo, somente se faz através de cidadãos conscientes e que possuam uma visão mais holística e menos cartesiana. Ver e se conscientizar que o custo da depleção será muito mais alto, e se não tivermos mais recursos naturais para explorar, o que será da humanidade, pois a visão de que tais recursos são infinitos é pura utopia.

Vivemos atualmente um quadro de incertezas e de demagogia. Fala-se muito em sustentabilidade, porém pratica-se pouco. Esta prática deve estar presente nas salas de aula, a fim de que se inicie uma cultura formativa de sustentabilidade alicerçada em seus três pilares, o social, o econômico e o ambiental.

O ramo do conhecimento das ciências administrativas é extremamente interdisciplinar. Tanto é que a sustentabilidade está presente em diversas matrizes curriculares dos mais variados cursos superiores e técnicos. Por ser assim, a sustentabilidade deveria ser uma temática constante no currículo dos cursos técnicos em administração. A formação de professores num mundo em constante mudança e com a necessidade de preparar os alunos para uma sociedade global exige que se atenda a aspectos distintos, dentre eles, a sustentabilidade.

O profissional de administração segundo Smith (1993) possui uma dificuldade muito grande em lidar com tal temática. Provavelmente, a sustentabilidade não tenha sido objeto de discussão em nenhuma cadeira do curso ou mesmo nem consta da grade curricular. Muitas vezes, o tema é tratado na forma de currículo oculto, por iniciativa de algum docente que encara a sustentabilidade relevante para a formação profissional e consegue construir relações com as outras disciplinas e situações do cotidiano, porém de forma implícita nos conteúdos. Os profissionais de administração formados em nossas instituições de ensino possuem uma ênfase formativa na parte gerencial, liderança, empreendedorismo e resultados (AMORIN \& CUSTÓDIO, 2010). 
Portanto, caso os profissionais de administração na sua formação sejam deficientes no que tange a sustentabilidade a sua atuação profissional na parte gerencial e mesmo empreendedora deixará de atender uma importante demanda do mercado e da sociedade, que atualmente veem na sustentabilidade um fator preponderante no desenvolvimento econômico aliado a manutenção e integridade do meio ambiente. Neste contexto o objetivo do nosso trabalho foi verificar qual a importância dada e se a temática da sustentabilidade está presente no currículo do Curso Técnico em Administração.

\section{REFERENCIAL TEÓRICO}

Nas últimas décadas testemunhamos a emergência do discurso da sustentabilidade como a expressão dominante no debate que envolve as questões de meio ambiente e de desenvolvimento social (LIMA, 2003), tanto no meio acadêmico como no empresarial e governamental, no Brasil e também nas demais nações, em vista das questões socioambientais se tornarem cobradas principalmente daqueles que se utilizam dos recursos naturais e do meio social para permanecerem e se perpetuarem em mercados competitivos (LANG, 2009).

A sustentabilidade pode ser considerada um conceito importado da ecologia, mas cuja operacionalidade ainda precisa ser provada nas sociedades humanas (ROSA, 2007). Entretanto, se por um lado a compreensão da sustentabilidade é necessária para promover mudanças, por outro as Instituições de Ensino Superior têm encontrado dificuldades para fomentar este entendimento (SHIRBERG, 2002).

Sustentabilidade nos remete ao vocábulo sustentar, no qual a dimensão longo prazo se encontra incorporada. Há necessidade de encontrar mecanismos de interação nas sociedades humanas que ocorram em relação harmoniosa com a natureza. "Numa sociedade sustentável, o progresso é medido pela qualidade de vida (saúde, longevidade, maturidade psicológica, educação, ambiente limpo, espírito comunitário e lazer criativo) ao invés de puro consumo material" (FERREIRA, 2005).

O termo deriva do comportamento prudente de um predador ao explorar sua presa, ou seja, moderação, por tempo indeterminado. Isto é, o ser humano necessitaria conhecer as particularidades do planeta para utilizá-lo por longo tempo assegurando a continuidade da própria espécie (SCHWEIGERT, 2007). O desenvolvimento sustentável será alcançado se três critérios forem obedecidos simultaneamente: equidade social, preservação ambiental e eficiência econômica (SACHS, 1993).

Barbieri (2007) afirma que os problemas provocados pelos humanos decorrem do uso do meio ambiente para obter os recursos necessários para produzir bens e serviços e do despejo de materiais e energia não aproveitados no meio ambiente. Entretanto, isso nem sempre gerou degradação ambiental, em razão da escala reduzida de produção e consumo e da maneira pela qual os seres humanos entendiam sua relação com a natureza e interagiam com ela.

Elkington (1998) elaborou o que atualmente conhecemos como os três pilares da sustentabilidade (Triple Botton Line), o econômico, o social e o ambiental, amplamente aceito e utilizado nas ciências administrativas. Diversas pesquisas vêm discutindo qual seria a melhor forma de integrar as dimensões da sustentabilidade nos currículos acadêmicos. Em especial para a área de administração e de negócios, esse tema vem adquirindo grande importância, tanto com 
relação a sua inclusão nos currículos acadêmicos (CHRISTENSEN, 2007; NOGUEIRA et al., 2007) quanto na sua adoção enquanto prática organizacional (BERINGER, 2008).

Segundo César \& Oliveira (2005), o currículo constitui-se como um mediador para práticas mais inclusivas, na medida em que faz a ponte entre os contextos institucionais mais alargados da escolarização e o micro-contexto da sala de aula, onde os professores e os estudantes se envolvem em aprendizagens acadêmicas. A construção de um currículo que pretendemos mais inclusivo fez emergir a necessidade de desenvolver nos professores uma consciência epistemológica que os leve a questionar as práticas, a refletir sobre elas, a implementar formas de trabalho colaborativo entre professores e os alunos (CÉSAR, 2003).

A educação ambiental como forma de atingir a sustentabilidade é tema que deve ser obrigatório do currículo escolar e repercute cada vez mais em soluções práticas de economia dos recursos renováveis e não renováveis. A coleta seletiva, por exemplo, serve aos propósitos de ensinar e reaproveitar, mas há a necessidade de avançar no conceito da sustentabilidade (FIGUEIREDO, 2010).

A sustentabilidade vincula-se a vários significados, os mais comuns dizem respeito à qualidade daquilo que se "protege", "conserva", "impede a ruína" e "anima". Pois mais do que empunhar a bandeira da preservação, é preciso mobilizar novas posturas de pais, alunos, professores e comunidade, entre outros, de forma a evitar o esgotamento ambiental. Isto trabalhando tanto sob a perspectiva do conteúdo curricular quanto da gestão dos recursos físicos e dos negócios no dia a dia escolar (FIGUEIREDO, 2010).

Tudo deve começar com o repensar do processo na formação do professor ou educador para a escola. Para modificar a escola, será imprescindível modificar, antes de tudo, a formação de seu professor (CAMARGO \& WOLF, 2008). Nesse sentido, Moraes (1998) cita que devemos trabalhar desde cedo com termos como a sustentabilidade, com o intuito de formar cidadãos conscientes dos valores ambientais.

Para ensinar sustentabilidade, as escolas precisam ficar mais sustentáveis, pois este é o local perfeito para se aprender, para dar os passos iniciais mudando algumas posturas administrativas, como, por exemplo, articulando-se com os fornecedores de sua região para adquirir os insumos e evitar grandes demandas por transporte (FIGUEIREDO, 2010).

A solução segundo Camargo \& Wolf (2008) não está em fazer da ecologia, sustentabilidade, uma disciplina obrigatória nos currículos, mas em educação ambiental escolar deve-se enfatizar o estudo do meio ambiente onde vive o aluno, procurando levantar os principais problemas da comunidade, as contribuições da ciência, os conhecimentos necessários e as possibilidades concretas para a solução deles.

O conceito de sustentabilidade não é tão fácil de lidar. Ele deve provocar a mudança de hábito numa sociedade acostumada às facilidades e vantagens oferecidas pela crescente tecnologia. A questão precisa ser discutida com mais profundidade (CAMARGO \& WOLF, 2008).

A formação de professores num mundo em mudança com a necessidade de preparar os alunos para uma sociedade global exige que se atenda a aspectos distintos, dentre eles, a sustentabilidade. As escolas estão cheias de alunos com uma diversidade de culturas e valores que importa preparar para a sociedade global (FREIRE, 2007). 
Existe dificuldade em programar um currículo colaborativamente com assuntos como a sustentabilidade (SÍTIMA, 2005). Os professores continuam a ler o currículo à luz das suas concepções de ensino e não interpretam os documentos como algo inovador. É, por isso, necessário investir na formação de professores (FREIRE, 2007).

O currículo é um dos locais privilegiados onde se entrecruzam saber e poder, representação e domínio, discurso e regulação (SILVA, 1996). O currículo é um campo composto de ideologia e cultura. Por ideologia segundo Moreira \& Silva (1997) pode-se afirmar que esta é a veiculação de ideias que transmitem uma visão do mundo social vinculada aos interesses dos grupos situados em uma posição de vantagem na organização social.

Alguns estudos realizados sobre currículo a partir das décadas 1960 a 1970 destacam a existência de vários níveis de Currículo: formal, real e oculto. O Currículo Formal refere-se ao currículo estabelecido pelos sistemas de ensino, é expresso em diretrizes curriculares, objetivos e conteúdos das áreas ou disciplina de estudo (SACRISTÁN, 2000). Este é o que traz prescrita institucionalmente os conjuntos de diretrizes como os Parâmetros Curriculares Nacionais. $O$ Currículo Real é o currículo que acontece dentro da sala de aula com professores e alunos a cada dia em decorrência de um projeto pedagógico e dos planos de ensino. O Currículo Oculto é o termo usado para denominar as influências que afetam a aprendizagem dos alunos e o trabalho dos professores. O currículo oculto representa tudo o que os alunos aprendem diariamente em meio às várias práticas, atitudes, comportamentos, gestos, percepções, que vigoram no meio social e escolar. O currículo está oculto por que ele não aparece no planejamento do professor (MOREIRA \& SILVA, 1997) e também não está na consciência dos responsáveis, mas é tratada de forma implícita em outros conteúdos, por exemplo, os papéis sociais, papéis sexuais e as atitudes com relação a muitos outros aspectos da vida (KELLY, 1981). O currículo oculto depende da postura, método e valores próprio professor (SILVA, 2015). O comportamento profissional dos professores está mais ligado com os efeitos ocultos das práticas e das instituições em que se formaram, do que com os conteúdos explícitos do currículo com que se pretendeu prepará-los (SACRISTAN \& GOMEZ, 1985).

\section{MÉTODO}

A referida seção aborda os procedimentos metodológicos utilizados a fim de atingir o objetivo proposto e confirmar ou não o pressuposto. A seguir são descritos os principais procedimentos utilizados nesta pesquisa e o pressuposto que direciona o estudo.

P: A temática sustentabilidade está inserida e é relevante no processo de ensino do curso Técnico em Administração do Colégio Politécnico.

\subsection{Delineamento da pesquisa}

O trabalho caracterizou-se como uma pesquisa exploratória quanto a sua finalidade, que segundo Hair et al. (2005) este tipo de pesquisa é utilizada quando tem-se poucas informações a cerca do objeto de pesquisa. Vergara (2011) diz que a pesquisa exploratória destina-se quando se sabe pouco ou quase nada sobre um determinado fenômeno ou objeto, possuindo uma natureza de sondagem. 
Com a finalidade de identificar a existência da sustentabilidade no currículo oficial do curso Técnico em Administração do Colégio Politécnico realizou-se uma pesquisa tipo documental a partir de dados secundários analisando-se o Projeto Político Pedagógico (PPP) e ementas das competências do Curso. Esta etapa da pesquisa classifica-se como documental, pois segundo Vergara (2011), se valerá da análise de documentos e registros internos da instituição.

Posteriormente realizou-se uma segunda etapa com uma pesquisa tipo qualitativa. De acordo com Malhotra (2006), a pesquisa qualitativa é um método não estruturado que se baseia em pequenas amostras que possibilitam, desta forma percepções e a compreensão do contexto referente ao objeto estudado. Esta etapa da pesquisa consta de um estudo de caso constituindose de um estudo profundo de poucos objetos (VERGARA, 2011).

\subsection{População e Amostra}

O Colégio Politécnico da Universidade Federal de Santa Maria foi escolhido devido a sua abrangência e importância informacional para a região Central do estado do Rio Grande do Sul. Para manter o anonimato das referidas organizações iremos referir-nos a elas por meio de letras. Segundo Gil (2010) para a realização desse tipo de entrevista se faz necessário um clima de receptividade, sendo importante assegurar ao entrevistado a confidencialidade dos dados por ele fornecidos, também se faz necessário expor o tempo para a coleta dos dados e um local adequado e tranquilo para realização da entrevista. Para manter o anonimato dos respondentes elaborou-se a seguinte codificação descrita na Tabela 1.

No total foi entrevistado, o coordenador do curso assim como mais seis docentes que ministram as competências no curso técnico pós-médio, de um universo de 18 docentes. 0 curso Técnico de Administração tem o intuito de formar um profissional comprometido com o desenvolvimento social e econômico, respeitando valores éticos, morais, culturais, sociais e ecológicos que contribuam para o desenvolvimento sustentável.

\subsection{Coleta de dados}

Para a obtenção das descrições experienciais de cada docente foi utilizada a coleta de dados proposta por Gil (2010) de uma entrevista semiestruturada, que segundo o referido autor, ao mesmo tempo em que permite a livre expressão do entrevistado, garante a manutenção de seu foco pelo entrevistador. É estruturada uma lista de questões como roteiro permitindo serem formuladas novas questões quando necessárias com o objetivo de aprofundar o assunto da sustentabilidade no curso de administração da escola, porém é necessária uma questão norteadora do estudo.

Tabela 1 - Codificação dos participantes da entrevista.

\begin{tabular}{c|c|c}
\hline Código do entrevistado & Formação & Tempo de docência \\
\hline R.A & Administração & 5 a 10 anos \\
\hline R.B & Administração & 10 a 20 anos \\
\hline R.C & Administração & 5 a 10 anos \\
\hline R.D & Administração & 1 a 5 anos \\
\hline R.E & Matemática e Física & Mais de 20 anos \\
\hline R.F & Administração & 5 a 10 anos \\
\hline R.G & Ciências Contábeis & 1 a 5 anos \\
\hline
\end{tabular}




\subsection{Análise e interpretação dos dados}

Após a obtenção das descrições experienciais (dados secundários e entrevistas) será realizada a análise destas descrições. A metodologia para a análise dos textos é o procedimento proposto por Gil (2010, p.139) descrito na Tabela 2.

Tabela 2 - Procedimento de análise.

\begin{tabular}{ll}
\hline 1. Leitura da descrição de cada informação; entrevistas; \\
\hline 2. Extração das assertivas significativas; \\
\hline 3. Formulação dos significados; \\
\hline 4. Organização dos significados em conjuntos de temas; \\
\hline 5. Integração dos resultados numa descrição exaustiva; \\
\hline 6. Elaboração da estrutura essencial do fenômeno; \\
\hline 7. Validação da estrutura essencial. & Fonte: Gil (2010).
\end{tabular}

A primeira etapa consistiu em ler completamente a entrevista a fim de ter uma visão do todo; a segunda teve o propósito de aprofundar-se nas questões mais relevantes destacando frases e palavras que são significativas e excluindo as que se repetem; na terceira etapa realizouse a formulação por parte dos pesquisadores dos significados, ou seja, que mensagem aquelas palavras traduzem é a denominada etapa critica, sendo sempre importante manter a fidelidade referente à informação do entrevistado; a quarta etapa caracterizou-se pela compilação destas informações em categorias em função da relevância; na quinta etapa foi realizado o detalhamento e análise aprofundada do tema; na sexta etapa realizou-se um confronto de ideias e informações entre os entrevistados, destacando os pontos divergentes e comuns das suas respostas e evidenciando as respostas mais relevantes e que maiores ênfases receberam relativo ao objeto da pesquisa e sua essencialidade.

\section{RESULTADOS E DISCUSSÕES}

\subsection{Resultados da etapa documental}

Com a finalidade de identificar a existência da sustentabilidade no currículo oficial do curso Técnico em Administração analisando-se o Projeto Político Pedagógico e ementas das competências.

\subsection{Projeto Político Pedagógico e Ementa da instituição de ensino}

Nesta fase da pesquisa foi realizado um estudo documental a cerca do projeto político pedagógico e as ementas do curso Técnico em Administração do Colégio Politécnico da UFSM.

Com base nessa análise verificou-se que inexiste a temática sustentabilidade nas disciplinas oferecidas pelo Curso, isto é não consta no PPP, muito menos nas ementas das competências como base tecnológica. Porém há um direcionamento de que se aborde de forma transversal nas disciplinas a temática da sustentabilidade, disciplinas estas como Gestão financeira, Gestão de Custos, Planejamento e Projetos, Markenting, Análise de Investimentos, Gestão de Pessoas, Qualidade e Práticas de Gestão, isto dito pelo coordenador do curso. 
Ocorre que a sustentabilidade não faz parte do currículo oficial do Curso Técnico em Administração, porém faz parte do currículo oculto, que foi objeto da etapa qualitativa onde a mesma procurou identificar a existência e prática da sustentabilidade no mesmo.

\subsection{Resultados da Pesquisa Qualitativa}

A etapa qualitativa deste estudo teve por finalidade identificar se a temática sustentabilidade está ou não inserida nos currículos do curso e a percepção a cerca da importância do tema na formação do futuro Técnico em Administração para o mercado de trabalho por parte dos docentes.

Desta forma pretende-se ampliar e aprofundar os conhecimentos de forma a criar um entendimento sobre a presença ou não da sustentabilidade no currículo.

\subsection{Relevância e necessidade de inclusão da sustentabilidade}

A fim de buscar corroborar e complementar a pesquisa documental realizou-se uma pesquisa qualitativa objetivando verificar qual a importância dada e se a temática da sustentabilidade está presente no currículo do Curso Técnico em Administração. Inicialmente buscou-se informações a cerca do curso em si, procurando verificar se não havendo a existência da temática no currículo formal, se a sustentabilidade estava presente de forma oculta e sua relevância na formação profissional e como habilidade e competência a ser desenvolvida pelos alunos do curso.

Em relação às questões que tratam da relevância da sustentabilidade na formação e na inclusão da temática nas competências a serem adquiridas pelos alunos, ressalta-se que os respondentes em sua totalidade afirmaram que a sustentabilidade é importante para a formação do Técnico em Administração o que pode ser demonstrado na fala dos docentes.

Sim. O técnico tem que ter conhecimento de seu papel na sustentabilidade (R.E) [...].

O conceito encontra-se inserido na área administrativa e com grande aplicabilidade (R.G).

Certamente que sim, pois além de representar diretamente na imagem das organizações, a preocupação com a sustentabilidade gera consciência no individuo com relação a aspectos sociais e ambientais indo além do meramente econômico (R.A).

Isto denota que os docentes do curso acreditam de fato que a temática possui uma importância fundamental para a área das ciências administrativas e que as empresas devem inserir-se neste contexto, sendo importante esta competência na formação profissional para o mercado de trabalho. Corroborando Oliveira et al., (2010) afirma que as questões ambientais vem ganhando crescente importância no contexto organizacional, público ou empresarial, em razão dos constantes alertas de cientistas e de organismos multilaterais sobre as consequências de um modelo de gestão sem responsabilidade ambiental, além da percepção dos gestores de que o aspecto é já importante para a decisão dos consumidores. 
As empresas devem atuar neste contexto", seguindo desta forma uma tendência mercadológica contemporânea (R.F).

A sustentabilidade como foi descrita anteriormente como possuidora de inserção na administração e, portanto tem aplicabilidade em todas as competências do curso como fica claro no relato abaixo descrito:

Temas como gestão sustentável, onde os processos devem recuperar o capital humano, natural e financeiro empregado, e depois a utilização da sustentabilidade como estratégia organizacional, com um cunho mais social (R.A) $[\ldots]$.

A administração tem estreita relação com o tema sustentabilidade, uma vez que tem sido cada vez mais exigido das organizações uma postura de responsabilidade social (R.A) [...].

Considerando os três eixos da sustentabilidade, o ambiental, o social e o econômico, o gestor tem de atuar buscando a sobrevivência de seu empreendimento (R.F).

Isto demonstra de que forma a sustentabilidade pode ter aplicação direta na administração como em demais áreas do conhecimento, pois é de fato uma temática transdisciplinar. Muitas vezes o tema é abordado nas disciplinas de forma implícita, tratado em determinados conteúdos de algumas disciplinas, o que demonstra que o tema faz parte do currículo oculto do curso de alguns docentes, porém não por todos. Ou seja, o tema é tratado, mas não aparece formalmente nos documentos do curso, e sua inserção no ambiente escolar se dá por pura iniciativa docente, que vê a temática, como fundamental na estratégia organizacional das empresas e na própria formação do aluno. O saber sustentável deve estar incluso na estratégia das empresas e como relatado anteriormente, é uma tendência mercadológica e porque não dizer planetária, pois a conservação dos recursos naturais afetam diretamente o futuro das empresas e de maneira mais grave e crítica a vida de toda a humanidade. Demonstrando a aplicabilidade da temática e a relevância para o futuro profissional que vai atuar no mercado Lash \& Wellington (2007) destacam a importância de que as empresas estejam o mais rápido possível preparadas para o desafio de uma gestão ambientalmente responsável, pois estas, certamente conseguirão evidência e alcançarão uma melhor vantagem competitiva. Desta maneira, a adequação das empresas aos conceitos e práticas do gerenciamento ambiental tornar-se-ia um diferencial desejável perante seus stakeholders. Portanto o saber sustentável é indispensável para o aluno em sua formação para tanto deve-se sempre fazer relações a cerca do tema com outros saberes.

De acordo aos respondentes a sustentabilidade não deve ser tratada de forma isolada e sim integrada às demais disciplinas de maneira transversal, ou seja, é um tema que permite fazer relações entre as demais competências do currículo do curso.

Uma formação que inclua a sustentabilidade como tema transversal. Este é um tema transversal que de certa forma permeia parte significativa das discussões (R.F). 
Acredito que a sustentabilidade não pode ser tratada de forma isolada, mas a cada conteúdo desenvolvido seja demonstrado e enfatizado como ficaria o seu desenvolvimento de modo sustentável (R.G).

Fica evidenciado pelo discurso que a temática da sustentabilidade é relevante e que não necessariamente deva conter no currículo uma competência específica, mas a sustentabilidade ser relacionada e abordada nas demais disciplinas do curso de uma maneira que a temática esteja integrada aos conteúdos ministrados a fim de que os alunos de fato desenvolvam as habilidades e competências esperadas. Isto vai ao encontro da interdisciplinaridade, onde faz-se relações com os demais saberes na construção do conhecimento e na solução dos problemas.

No Brasil, a abordagem da temática ambiental para formação foi, inclusive, regulamentada pela Lei no. 9.795, de 27 de abril de 1999 (Política Nacional de Educação Ambiental no Brasil), que definiu a obrigatoriedade de se abordar o tema ambiental de forma transversal nos currículos escolares.

\subsection{Sustentabilidade na percepção do docente no processo educacional}

A percepção do docente relativo a sustentabilidade é que o tema é importante e deve estar inserido no processo educacional dos alunos do Curso Técnico em Administração. Porém esta inserção se dá de forma espontânea e por iniciativa própria de cada docente, já que a sustentabilidade não está formalmente integrando o Currículo e o PPP do curso.

Alguns docentes já trabalham a temática em algum conteúdo de suas disciplinas de forma geralmente superficial e em alguns projetos de cunho sustentável.

A escola é formada por professores, assim acredito que as oportunidades ocorram através dos professores, entendo a escola como direção, acredito que o papel da direção é de apoiar as iniciativas vinda dos professores e na criação de oportunidades, talvez inclusive sensibilizar o corpo docente através de palestras e das diretrizes, mas cabe ao professor tomar a iniciativa de trabalhar com projetos sustentáveis (R.G) [...].

O tema sustentabilidade é abordado em minhas competências de forma transversal, não constando nos conteúdos programáticos, ou seja, nas bases tecnológicas a serem desenvolvidas (R.D).

Evidencia-se que a temática para ser abordada depende exclusivamente do corpo docente e se este não possuir esta percepção ou mesmo o conhecimento necessário, a temática não é abordada na sala de aula. Em relação à dimensão ambiental segundo os relatos, alguns docentes abordam o tema de forma genérica.

Mais ou menos. Se tivesse que trabalhar especificamente o tema sustentabilidade seria necessário estudar muito mais o tema (R.F) [...].

Afirmar que eu esteja preparado ou pronto é uma grande ilusão, afinal necessitamos sempre de constante atualização, envolvimento e motivação (R.G).

Me sinto preparada para discutir o tema de forma ampla, mas para que seja possível um envolvimento com a parte ambiental seria necessário qualificação (R.D). 
Não são todos os professores que abordam a dimensão ambiental da sustentabilidade em suas competências, até porque Ihes faltam subsídios informacionais para tanto, sendo difícil inclusive fazer relações com as competências que proferem aula, e desta maneira tratando o tema de forma superficial e genérica. Porém alguns docentes tratam do tema sustentabilidade de forma integrada aos demais conteúdos transmitidos até pela própria formação acadêmica ser diferente das ciências sociais e humanas onde o tema ambiental não é tratado de forma mais profunda, possuindo uma formação na área das engenharias, biologia e exatas as quais relacionam de forma mais holística e integrada os pilares que baseiam a sustentabilidade.

Sim, trabalho com produção mais limpa, sistemas autossustentáveis. Pode ser integrada com as demais (R.E).

O ideal é mesmo trabalhar de forma integrada a sustentabilidade as demais competências do curso que constam no Projeto Politico Pedagógico. Não ocorrendo esta inclusão a abordagem da temática se dá exclusivamente pelo interesse dos professores que sentem-se preparados para tratar da temática de forma transversal como foi descrito nos relatos. Isto é uma amostra de interdisciplinaridade, mas esta deve vir da direção da escola e constar oficialmente do PPP do curso como proposta pedagógica na formação dos futuros técnicos em administração formados pela escola.

\section{CONSIDERAÇÕES FINAIS}

A sustentabilidade tem sido um tema bastante discutido a tal ponto de que a partir da Rio +20 realizada no ano de 2012 , em um compromisso assumido pelas nações participantes, que este tema comece a fazer parte das matrizes curriculares dos cursos em diferentes níveis. Isto denota a relevância da sustentabilidade para o futuro da humanidade, não sendo atualmente admissível um profissional que não saia ao menos com uma noção do tema.

De acordo com o objetivo da pesquisa em verificar a presença e importância da sustentabilidade no currículo do Curso Técnico em Administração, verificou-se que não existe nenhuma disciplina sobre o tema no currículo oficial. Porém a sustentabilidade é abordada de forma particular e implícita por alguns professores do curso em suas disciplinas sempre fazendo relações com o conteúdo da aula e não tratando essa temática de forma direta como a narrativa RD, explicitada na página 11 segundo parágrafo.

Verificou-se que alguns docentes identificaram a necessidade de mais estudos para abordarem a sustentabilidade mesmo quando integradas as disciplinas que ministram. Sendo unânime o discurso de que a sustentabilidade é de extrema importância na formação do profissional técnico em administração e de sua alta aplicabilidade na área, sendo um tema transversal e que não deve ser tratado de forma isolada.

\section{REFERÊNCIAS BIBLIOGRÁFICAS}

1. AMORIM, R.C.M; CUSTÓDIO, L.S.; A necessidade de estruturação dos pressupostos da sustentabilidade e da responsabilidade social empresarial para as realidades do ensino/aprendizagem nos cursos de administração. E-civitas: Revista Científica do Departamento de Ciências Jurídicas, Políticas e Gerenciais do UNI-BH, v.3, n.1, p.1-20. 2010. 
2. BARBIERI, J.C. Gestão Ambiental Empresarial: conceitos, modelos e instrumentos. 2. ed. São Paulo: Saraiva, 2007. 382p.

3. BERINGER, A.; TARAH, W.; MALONE, T. Sustainability in higher education in Atlantic Canada. International Journal of Sustainability in Higher Education, v.9, n.1, p.48-67. 2008.

4. BRASIL. Lei no 9.795, de 27 de abril de 1999. Dispõe sobre a educação ambiental, institui a Política Nacional de Educação Ambiental e dá outras providências. Diário Oficial da União, Brasília, DF, 28 de abril de 1999. Disponível em: <http://www.planalto.gov.br/CCIVIL/LEIS/ L9795.htm>. Acesso em: 04 dezembro 2012.

5. CAMARGO, R.; WOLF, R.A.P. Educação ambiental e cidadania no currículo escolar. Revista Eletrônica Lato Sensu - UNICENTRO, n.6, p.3-23. 2008.

6. CÉSAR, M.A. Escola Inclusiva Enquanto Espaço-Tempo de Diálogo deTodos e para Todos. In: David Rodrigues (Ed.). Perspectivas Sobre a Inclusão da Educação à Sociedade. Porto: Porto Editora, p.118-149, 2003.

7. CÉSAR, M.; OLIVEIRA, I. The curriculum as a mediating tool for inclusive participation: A casestudy in a Portuguese multicultural school. European Journal of Psychology of Education, v.1, p.29-43. 2005.

8. CHRISTENSEN, L.J.; PIERCE, E.; HARTMAN, L.P., HOFFMAN, W.M.; CARRIER, J. Ethics, CSR and sustainability education in the financial times top 50 global businessschools: Baseline data and future research directions. Journal of Business Ethics, v.73, p.347-368. 2007.

9. Colégio Politécnico da UFSM. Projeto Pedagógico. Universidade Federal de Santa Maria. Ministério da Educação, 2011.

10. ELKINGTON, J. Cannibals with forks. The Triple Botton Line of $21^{\text {st }}$ Century Business. Filadélfia: New Society, 1998. 488p.

11. FERREIRA, L.C. Sustentabilidade: uma abordagem histórica da sustentabilidade. In: BRASIL. Encontros e Caminhos: Formação de Educadoras (es) Ambientais e Coletivos Educadores. Brasília: Ministério do Meio Ambiente, 2005. 357p.

12. FIGUEIREDO, R. Especial: escolas verdes, 2010. Disponível em: <http://www.direcional escolas.com.br/edicao-61-set/10/especial-escolas-verdes>. Acesso em: 29 de maio de 2012

13. FREIRE, A.M. Educação para a Sustentabilidade: Implicações para o Currículo Escolar e para a Formação de Professores. Pesquisa em Educação Ambiental, v.2, n.1, p.141-154, 2007.

14. GIL, A.C. Como elaborar projetos de pesquisa. 5. Ed., São Paulo: Atlas, 2010. 184p.

15. HAIR, J.F. Jr.; BABIN, B.; MONEY, A.; SAMOUEL, P. Fundamentos de métodos de pesquisa em Administração. Porto Alegre: Bookman, 2005. 471p.

16. KELLY, A.V. O Currículo: teoria e prática. São Paulo: Harper \& Row do Brasil, 1981.164p.

17. LANG, J. Gestão ambiental: estudo das táticas de legitimação utilizadas nos relatórios da administração das empresas listadas no ISE. Blumenau, 2009. Dissertação de mestrado Universidade Regional de Blumenau, 2009. 124p.

18. LASH, J.; WELLINGTON, F. Competitive advantage on a warming planet. Harvad Business Review, v.85, p.95-102, 2007.

19. LIMA, G. C. O discurso da sustentabilidade e suas implicações para a educação. Ambiente e sociedade. v.6, n.2. p.99-120. 2003. 
20. MALHOTRA, K.N. Pesquisa de marketing: uma orientação aplicada. 4. ed. Porto Alegre: Bookman, 2006. 720p.

21. MORAES, E.C. A construção do conhecimento integrado diante do desafio ambiental: uma estratégia educacional. In: Tendências da educação ambiental Brasileira. NOAL, F.; REIGOTA, M.; BARCELOS, V. Santa Cruz do Sul: Edunisc, p.28-34. 1998.

22. MOREIRA, A.F.B.; SILVA, T.T. Currículo, cultura e sociedade. 2. ed. São Paulo: Cortez, 1997. $176 \mathrm{p}$.

23. NOGUEIRA, E.A.T.; CARVALHO, G.M.; NASCIMENTO, J.P.B.; BERNARDO, D.C.R.; TEXEIRA, D.L. Do Verbo à Ação na Inovação Curricular: um Estudo de Caso e numa Instituição Federal de Ensino Superior. In: SEMEAD, X, 2007, São Paulo. Anais eletrônicos... São Paulo: FEA-USP, p. 01-15. 2007.

24. OLIVEIRA, L.G.L.; OLIVEIRA, D.M.; COSTA, F.G.A gestão ambiental nos cursos de administração: uma análise da perspectiva dos professores. Revista de Administração da UFSM, v.3, n.2, p.205-218. 2010.

25. Relatório Rio+20: o Modelo Brasileiro - Relatório de Sustentabilidade da Organização da Conferência das Nações Unidas sobre Desenvolvimento Sustentável. Brasília, 2012.

26. ROSA, A. Rede de governança ambiental na cidade de Curitiba e o papel das tecnologias de informação e comunicação. Curitiba. 2007. Dissertação de mestrado - Gestão Urbana Pontifícia Universidade Católica do Paraná, 2007. 194p.

27. SACHS, I. Estratégias de transição para o século XXI: desenvolvimento e meio ambiente. São Paulo: Nobel, 1993. 103p.

28. SACRISTÁN, J.G. O Currículo: uma reflexão sobre a prática. 3. ed. Porto Alegre: Artmed, 2000. $123 p$.

29. SACRISTAN, J.G. \& GOMEZ, P.A. La enseñanza: su teoria y su prática. Madrid: Akal, 1985.

30. SILVA, M.J.L. Função ideológica da escola: o currículo oculto, 2015. Disponível em: < http://www.senac.br/informativo/bts/222/boltec222e.htm >. Acesso em: 10 de janeiro de 2015

31. SMITH, D. As empresas e o ambiente: implicações do novo ambientalismo. Lisboa: Instituto Piaget, 1993. 326p.

32. SCHWEIGERT, L.R. Plano diretor e sustentabilidade ambiental da cidade. São Paulo. 2007. Dissertação de mestrado - Arquitetura e Urbanismo - Universidade Presbiteriana Mackenzie, 2007.

33. SHRIBERG, M. Institutional Assessment Tools for sustainability in higher education Strengths, weaknesses, and implications for practice and theory. International Journal of Sustainability in Higher Education, v.3, n.3, p.257-270. 2002.

34. SILVA, T.T. Identidades terminais: as transformações na política da pedagogia e na pedagogia da política. Petrópolis: Vozes, 1996. 273p.

35. SÍTIMA, M.A.B. Implementar colaborativamente o currículo de Ciências Físicas e Naturais. Lisboa, 2005. Dissertação de Mestrado - Universidade de Lisboa - Faculdade de Ciências, 2005.

36. VERGARA, S.C. Projeto e Relatório de Pesquisa em Administração. Atlas: São Paulo, 2011. $94 p$. 